\title{
Oxidation Prevention and Electrical Property Enhancement of Copper-Filled Isotropically Conductive Adhesives
}

\author{
MYUNG JIN YIM, ${ }^{1}$ YI LI, ${ }^{1}$ KYOUNG SIK MOON, ${ }^{1}$ and C.P. WONG $^{1,2}$ \\ 1.-School of Materials Science and Engineering, Georgia Institute of Technology, 771 Ferst \\ Drive, Atlanta, GA 30332, USA. 2.—e-mail: cp.wong@mse.gatech.edu
}

This paper describes the development and characterization of isotropically conductive adhesives (ICAs) incorporating copper $(\mathrm{Cu})$ powders as electrically conductive fillers, along with a silane coupling agent for oxidation protection of copper powders, for environmentally friendly, low cost and high thermal reliability applications in microelectronics packaging. The effect of silane coupling agent materials and concentration on the electrical conductivity, thermal stability and reliability of $\mathrm{Cu}$-filled ICAs was investigated for potential alternatives of conventional silver-filled ICAs. The surface characteristics of silane thin films on copper surfaces, such as their hydrophobicity and thermal stability, were also evaluated to compare the performance of antioxidant behaviors of different silane coupling agents for Cu-filled ICAs. The low contact resistance and high thermal stability of the contact resistance of $\mathrm{Cu}$ filled ICAs were achieved by addition of an optimized silane coupling agent. Greater thermal stability and improved reliability of $\mathrm{Cu}$-filled ICAs under high temperature and humidity conditions were achieved with a silane coupling agent of high molecular weight and hydrophobicity. The bulk resistivity of $\sim 10^{-4} \Omega \mathrm{cm}$ of Cu-filled ICAs was achieved with bimodal filler loading.

Key words: Isotropic conductive adhesive (ICA), copper, antioxidant, silane coupling agent, electrical contact resistance, reliability

\section{INTRODUCTION}

Isotropically conductive adhesives (ICAs) are being used to replace the traditional eutectic $\mathrm{SnPb}$ and $\mathrm{Pb}$-free solder alloys in electronic packaging and interconnections. ${ }^{1,2}$ They are composites of polymer resin and conductive fillers. The polymer resins and thermoplastic or thermosetting resins, generally cured at high temperature, are used as ICA matrix resin and provide the shrinkage force and adhesion strength, and good chemical and corrosion strength. Epoxy, cyanate ester, silicone, and polyurethane are typical thermosetting resins, and phenolic epoxy and polyimide are common thermoplastics, for ICA matrix resin. Conductive fillers include silver $(\mathrm{Ag})$, gold $(\mathrm{Au})$, nickel $(\mathrm{Ni})$, copper $(\mathrm{Cu})$ and tin $(\mathrm{Sn})$, tin-bismuth $(\mathrm{SnBi})$ or tin-indium

(Received December 14, 2006; accepted May 15, 2007;

published online August 18, 2007)
( $\mathrm{SnIn}$ ) coated $\mathrm{Cu}$ in various sizes and shapes. $\mathrm{Ag}$ is the most common conductive fillers for ICA, due to its high conductivity and easy processing, but its high cost is one of the drawbacks for wide use of Ag-filled ICAs. ICAs have been used for die attach adhesives, ${ }^{3}$ adhesives in surface mount technology (SMT), ${ }^{4,5}$ and flip chip ${ }^{6}$ and other applications. Figure 1 shows the schematics of SMT and flip chip components assembled by ICA joints instead of solder joints. However, current ICAs still have some limitations in terms of their electrical, thermal, and reliability properties, compared with those of lead or lead-free solders, for solder replacement purpose.

Therefore, many research efforts have been focused mainly on the improvement of electrical conductivity and reliability performance of ICA joints. Also, the replacement of expensive Ag flakes by new metal flakes has been pursued for the wide use of ICAs instead of solder materials. Copper can be a promising candidate for conductive filler metal, due to its low resistivity, low cost and improved 

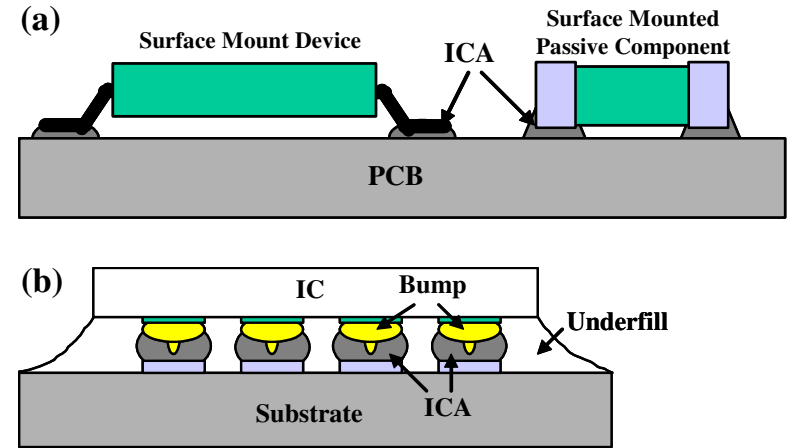

Fig. 1. Schematic structures of (a) surface mount interconnection using ICA, and (b) flip chip interconnection using ICA.

electro-migration performance, but oxidation causes this metal to lose its conductivity. ${ }^{7}$

There are, basically, two approaches to surface treatment on copper fillers for ICA application. One is inorganic material coating, and the other is organic material coating. For inorganic coating materials, silver, gold and nickel/gold and solder materials, such as Sn and InSn, are some examples which are coated by electro- or electroless deposition. ${ }^{8}$ For organic coating materials on copper surfaces for oxidation/corrosion protection, self-assembly monolayer (SAM) formation, such as azole or thiol compounds,,${ }^{9,10}$ and organosilicic compound formation ${ }^{11}$ are the representatives; however, their poor thermal stabilities are concerns, because most of the coatings lose their effectiveness when exposed to the curing condition of ICAs.

For self-assembly monolayer formation, dodecanethiol (DT), mercaptobenzothiazole (MBT), benzotriazole (BTA), imidazole (IMD), or benzothiazole (BT) can be formed on the surface of copper films, ${ }^{9}$ but they are not useful, due to low thermal stability for the coating layer on the copper filler in ICAs, which is normally cured at $150^{\circ} \mathrm{C}$ for $30-60 \mathrm{~min}$. Also SAM layer of hexadecanthiol (HDT) on oxidized and clean copper surfaces ${ }^{10}$ can be formed, but its poor thermal stability above $150^{\circ} \mathrm{C}$ is one drawback for an organic protection layer on copper fillers in electrically conductive adhesives (ECAs). For organosilicic compound formation, methyltriethoxysilane (MTES) ${ }^{11}$ is used to maintain the luster and high electric conductivity and to prevent the oxidation of copper metal, but this silane is not effective in preventing $\mathrm{Cu}$ oxidation at the cure condition of a typical ICA formulation.

In this study, we developed and characterized the $\mathrm{Cu}$-filled ICAs by using novel silane coupling agents for oxidation prevention of $\mathrm{Cu}$ fillers for conventional ICA applications. The effect of the materials and concentrations of silane coupling agents on the electrical conductivity, high thermal stability, and reliability of $\mathrm{Cu}$-filled ICAs was investigated for potential alternatives of conventional silver-filled ICAs. We also evaluated the surface characteristics of silane thin films on copper surfaces, such as their hydrophobicity and thermal stability, to compare the antioxidant behaviors of different silane coupling agents in $\mathrm{Cu}$-filled ICAs.

\section{EXPERIMENTS}

\section{Preparation of Materials}

We formulated the Cu-filled ICA by the in situ mixing of silane coupling agent with $\mathrm{Cu}$ powder by the following procedure: The copper powders were dipped in $10 \% \mathrm{HNO}_{3}$ solution, to remove native oxide layers on the surfaces of the $\mathrm{Cu}$ powders, and washed with deionized (DI) water and methanol, twice, and then dried at room temperature under a nitrogen atmosphere.

For the ICA formulation, we used a mixture of liquid epoxy resin, anhydride hardener, and imidazole catalyst for the polymer matrix system and added $\mathrm{Cu}$ powders up to $80 \mathrm{wt} \%$. Two silane coupling agents were added to the ICA formulation, with variation of concentrations and types. The first coupling agent (CA 1) had an aliphatic structure, and the second (CA 2) had an aromatic structure.

The Cu-filled ICAs were cured at $150^{\circ} \mathrm{C}$ for 60 min on a digital hot plate and in a convection oven. For the bimodal filler loading of $\mathrm{Cu}$ fillers in the ICA formulation, we prepared $\mathrm{Cu}$ powders, which were composed of particles with 30-40 $\mu \mathrm{m}$ diameters, and followed the same procedure as for the acid treatment. We rinsed them to obtain oxidefree $\mathrm{Cu}$ powders and formulated ICA composite with $\mathrm{Cu}$ powders of $1-5 \mu \mathrm{m}$ diameter (40 wt.\%) and 30-40 $\mu \mathrm{m}$ diameter (40 wt.\%), respectively. The bulk resistivity of the Cu-filled ICA in bimodal filler loading with optimized silane coupling agents was measured after the thermal curing process.

Scanning electron microscopy (SEM) was used for the cross-sectional view of Cu-filled ICA, using a Hitachi S-800 FE-SEM.

\section{Electrical Conductivity and Reliability Test}

The effect of the silane coupling agents on the electrical conductivity of $\mathrm{Cu}$-filled ICA composite was characterized by the in situ measurement of the electrical contact resistance during the curing of $\mathrm{Cu}$-filled ICA. The effect of the content of the silane coupling agents on the thermal stability of the electrical contact resistance of cured $\mathrm{Cu}$-filled ICA was evaluated by the monitoring of the contact resistance of $\mathrm{Cu}$-filled ICA with increasing temperature up to $270^{\circ} \mathrm{C}$. The thermal stability of the electrical contact resistance of $\mathrm{Cu}$-filled ICA with different silane coupling agents during a multiple reflow process was also evaluated. The bulk resistivities of $\mathrm{Cu}$-filled ICA materials with different silane coupling agents in optimized concentrations were measured. The schematics of contact resistance and bulk resistivity measurement of $\mathrm{Cu}$-filled ICAs are shown in Fig. 2.

The bulk resistivities and the reliabilities of $\mathrm{Cu}$-filled ICAs with different silane coupling agents 
(a) Contact Resistance $\left(\mathrm{C}_{\mathrm{R}}\right)$ Measurement

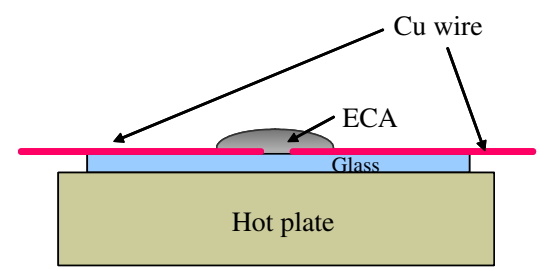

(b)

Bulk Resistance Measurement

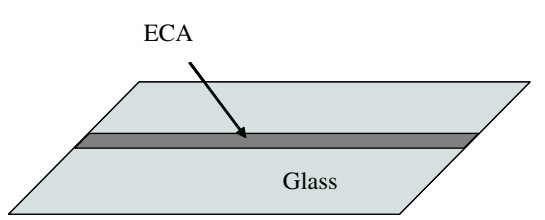

Fig. 2. Schematic drawings of (a) contact resistance and (b) bulk resistance measurements of Cu-filled ICAs.

were assessed by the bulk resistivity behaviors of $\mathrm{Cu}$-filled ICAs under conditions of high temperature/humidity and high temperature/dryness for $24 \mathrm{~h}$. The Cu-filled ICAs with bimodal distribution of $\mathrm{Cu}$ fillers with optimized silane coupling agent was finally prepared, and its bulk resistivity was measured.

\section{Contact Angle Measurement}

To prove the hydrophobicity of the silane coating layer on the $\mathrm{Cu}$ surface, we investigated the contact angle behavior of the silane coating layer on the surface of a $\mathrm{Cu}$ plate. A thin copper plate was cut into approximately $1 \mathrm{~cm}^{2}$ pieces with a low speed saw. We prepared 5 wt.\% and 10 wt.\% of CA 1 and CA 2 ethanol solutions and used them to treat the copper plates, respectively. The immersion time of copper in a silane solution was 10,30 , or $50 \mathrm{~min}$. After being treated in the silane solution, the copper was cured in the oven at $130^{\circ} \mathrm{C}$ for $30 \mathrm{~min}$, as indicated in Table I.

We measured the contact angle at three locations on each sample surface by dropping deionized (DI) water onto the plate using an automatic pipette and the computer system of a goniometer (Rame-Hart Co.). The ten measurements at the three locations were all averaged to provide a mean contact angle for that sample. Two of the combinations of dipping time and curing temperature were recreated for each silane solution so that the effect of aging on the contact angle could be tested. The samples were dipped for $30 \mathrm{~min}$ in the silane solution and cured at $130^{\circ} \mathrm{C}$ for $30 \mathrm{~min}$. Untreated samples were also prepared as before. All of the samples, as shown in

Table I. The Combination of Variables used in the Samples for Contact Angle Measurement of Silane Coating Layer on Copper Substrate. Untreated Samples were also Prepared

\begin{tabular}{lccc}
\hline $\begin{array}{l}\text { Silane } \\
\text { Solution (\%) }\end{array}$ & $\begin{array}{c}\text { Dipping } \\
\text { Time (min) }\end{array}$ & & $\begin{array}{c}\text { Curing } \\
\text { Temperature }\left({ }^{\circ} \mathbf{C}\right)\end{array}$ \\
CA 1 \& 2, 5\% & & 10 & 130 \\
CA 1 \& 2, 5\% & 30 & 130 \\
CA 1 \& 2, 5\% & 50 & 130 \\
CA 1 \& 2, 10\% & 10 & 130 \\
CA 1 \& 2, 10\% & 30 & 130 \\
CA 1 \& 2, 10\% & 50 & 130 \\
\hline
\end{tabular}

Table II, were aged at $50,100,150$, or $200^{\circ} \mathrm{C}$ for $10 \mathrm{~min}$ in the oven before being tested.

\section{RESULTS AND DISCUSSION}

\section{Effect of Coupling Agent on Electrical Contact Resistance of Cu-Filled ICAs During the Cure Process}

Figure 3 shows the change in contact resistance for two uncured $\mathrm{Cu}$-filled formulations, with or without the coupling agent, as a function of time during curing, where the temperature profile $\left(150^{\circ} \mathrm{C}\right.$ for $60 \mathrm{~min}$ ) is co-plotted. At the beginning of the heating profile, the contact resistance decreased initially and increased gradually until the end of the thermal cure process. After the cure process, the temperature was lowered to room temperature by natural cooling. At room temperature, the cured $\mathrm{Cu}$-filled ICAs without the coupling agent still showed a very high contact resistance, of around the $100 \mathrm{M} \Omega$ range, while the cured $\mathrm{Cu}$-filled ICAs with the coupling agent showed a very low contact resistance of around $0.3 \Omega$. This improvement may be attributed to the antioxidant role of the coupling agent, and the coupling agent used was effective in obtaining low bulk resistance by protecting the $\mathrm{Cu}$ powders from oxidation during thermal cure at $150^{\circ} \mathrm{C}$. Thus, we found that the addition of a silane coupling agent to the $\mathrm{Cu}$-filled ICA formulation was effective for the low contact resistance of $\mathrm{Cu}$-filled

Table II. The Combination of Variables for the Aging Effect on Contact Angle Measurement of Silane Coating Layers on Copper Substrates. Each sample was dipped in the silane solution for $30 \mathrm{~min}$, cured for $30 \mathrm{~min}$, and aged for $10 \mathrm{~min}$

\begin{tabular}{lcc}
\hline $\begin{array}{l}\text { Silane } \\
\text { Solution (\%) }\end{array}$ & $\begin{array}{c}\text { Curing } \\
\text { Temperature } \\
\left({ }^{\circ} \mathbf{C}\right)\end{array}$ & $\begin{array}{c}\text { Aging } \\
\text { Temperature } \\
\left({ }^{\circ} \mathbf{C}\right)\end{array}$ \\
\cline { 2 - 2 } CA 1 \& 2, 5\% & 130 & 50 \\
CA 1 \& 2, 5\% & 130 & 100 \\
CA 1 \& 2, 5\% & 130 & 150 \\
CA 1 \& 2, 5\% & 130 & 200 \\
CA 1 \& 2, 10\% & 130 & 50 \\
CA 1 \& 2, 10\% & 130 & 100 \\
CA 1 \& 2, 10\% & 130 & 150 \\
CA 1 \& 2, 10\% & 130 & 200 \\
\hline
\end{tabular}




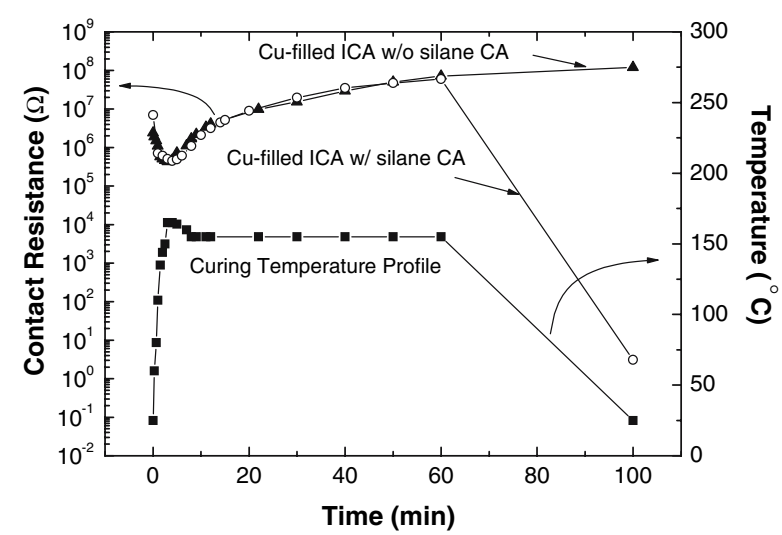

Fig. 3. In situ measurement of resistance of Cu-filled ICA during thermal cure.

ICA composite during the typical thermal cure condition of ICAs.

Figure 4 shows the SEM cross-sectional view of cured $\mathrm{Cu}$-filled ICA. It shows the bimodal distribution of $\mathrm{Cu}$ flakes, and the contacts and interfaces between $\mathrm{Cu}$ flakes in the ICA. The intimate contacts between $\mathrm{Cu}$ flakes are essential for electrical conduction through the network of the $\mathrm{Cu}$ flakes in the ICA materials.

\section{Effect of Concentration of Silane Coupling Agent on Thermal Stability of Copper-Filled ICA}

While the silane coupling agent is effective in preventing $\mathrm{Cu}$ powder oxidation, there is still concern about the electrical stability of cured $\mathrm{Cu}$-filled ICAs at elevated temperatures, such as a reflow temperature over $250^{\circ} \mathrm{C}$. The substrate on which the $\mathrm{Cu}$-filled ICAs are used as either chip bonding or

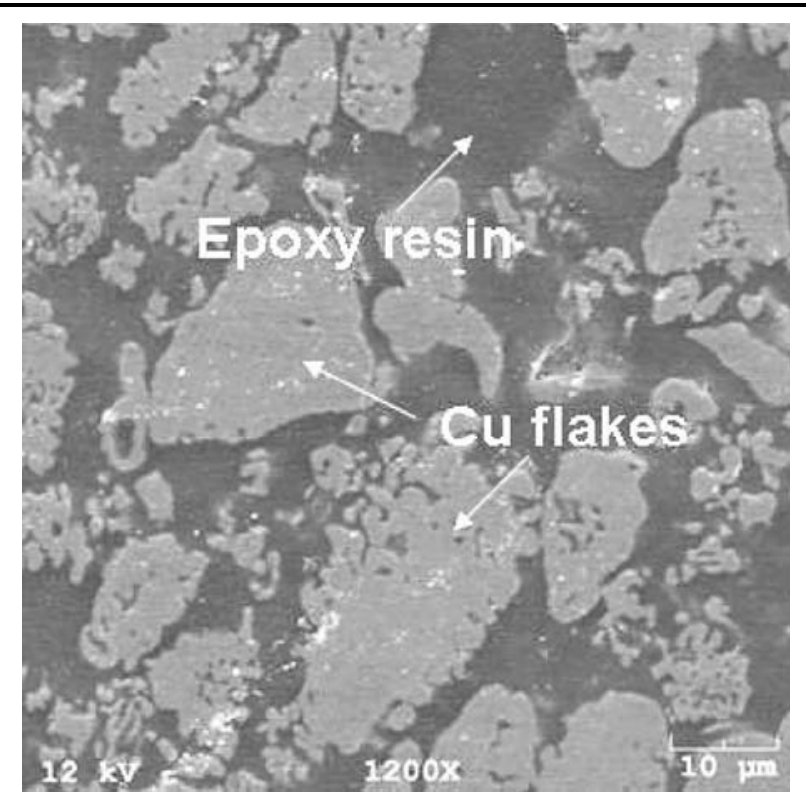

Fig. 4. Cross-sectional SEM picture of Cu-filled ICA materials.

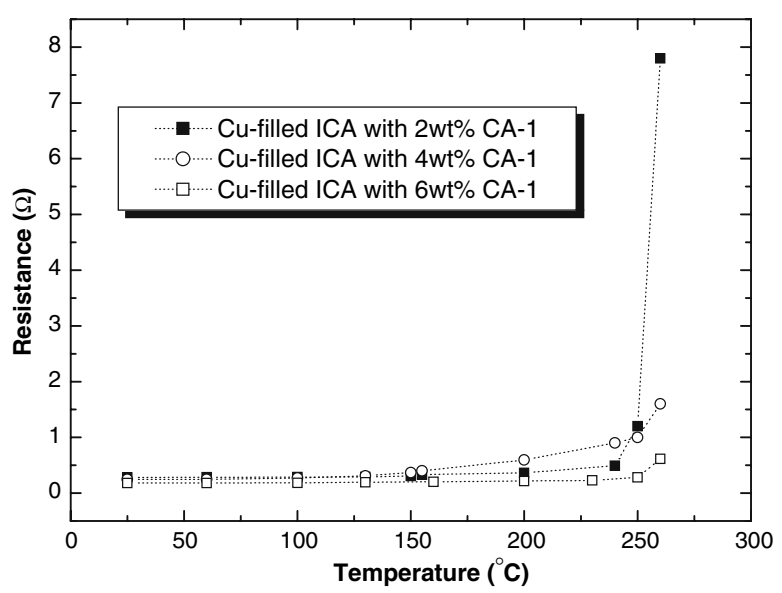

Fig. 5. Temperature dependence of bulk resistance of Cu-filled ICA composite with different concentrations of silane coupling agent.

via filling can experience the typical reflow processes. Therefore, we monitored the contact resistance of $\mathrm{Cu}$-filled ICAs with the coupling agent between two $\mathrm{Cu}$ wire electrodes during a temperature variation from $30^{\circ} \mathrm{C}$ to $260^{\circ} \mathrm{C}$ to investigate the thermal stability of the electrical property of $\mathrm{Cu}$-filled ICA joints.

Figure 5 shows the temperature dependency of the contact resistances of $\mathrm{Cu}$-filled ICAs with different concentrations of CA 1 . The contact resistance was stable up to $150^{\circ} \mathrm{C}$, while it increased slightly at higher temperatures. Cu-filled ICAs with 2,4 , and 6 wt.\% CA 1 exhibited $\sim 2,700,700$, and $300 \%$ increase in resistance at $260^{\circ} \mathrm{C}$, respectively. As the concentrations of the coupling agent increased, the thermal stability of the bulk resistance of copper-filled ICA improved. This result indicates that the addition of optimized amounts of coupling agent is also effective in improving the thermal stability of the electrical property of Cu-filled ICA joints, presumably by protecting further oxidation of copper powder at elevated temperature.

\section{Effect of Type of Coupling Agent on Thermal Stability of Cu-Filled ICAs}

The contact resistances of ICA joints should be stable under harsh environmental conditions. Especially, the thermal oxidation at the surfaces of $\mathrm{Cu}$ flakes, or at the interfaces between $\mathrm{Cu}$ flakes and electrodes, due to elevated temperature from multiple reflow processes may be one of the main failure mechanisms of $\mathrm{Cu}$-filled ICA joints. We evaluated the thermal stability of such joints with different types of coupling agents by measuring contact resistance during multiple reflow processes.

Figure 6 shows the contact resistance of $\mathrm{Cu}$-filled ICAs with different coupling agents with increasing temperature. As the temperature increases, the $\mathrm{Cu}$ filled ICA with 6 wt.\% CA 1 showed stable contact resistance up to $200^{\circ} \mathrm{C}$, but, after $200^{\circ} \mathrm{C}$, contact resistance increased dramatically. On the other hand, the Cu-filled ICA with 6 wt.\% CA 2 showed 


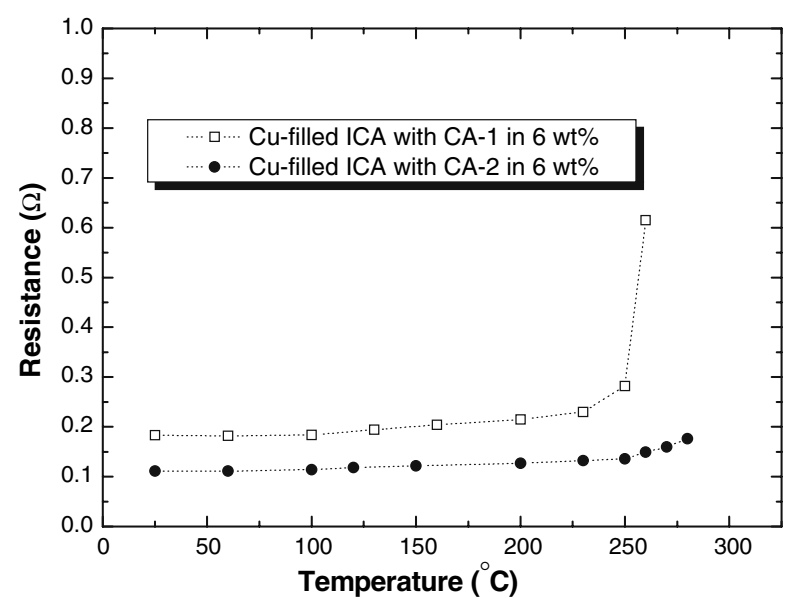

Fig. 6. Thermal stability of contact resistance of Cu-filled ICA with different silane coupling agents.

lower contact resistance and more stable contact resistance up to $280^{\circ} \mathrm{C}$ than that with $\mathrm{CA} 1$. This means that CA 2 is more effective in reducing the thermal oxidation of $\mathrm{Cu}$ powders in $\mathrm{Cu}$-filled ICAs.

Figure 7 shows the changes in resistance of $\mathrm{Cu}$ filled ICAs with different CAs during triple reflow processes. The $\mathrm{Cu}$-filled ICA with $\mathrm{CA} 2$ was more stable than that with CA 1 . This result indicates that CA 2 has superior oxidation-preventing capability than does CA 1 in Cu-filled ICA joints, due to the greater thermal stability of CA 2 . The greater thermal stability of CA 2, with its aromatic structure, is related to its higher boiling temperature $\left(T_{\mathrm{b}}\right)$, due to its benzene ring and thermally more stable structure than $\mathrm{CA} 1$, with its aliphatic structure. These results also confirm that the CA coating on the surface of copper powder is very effective in preventing the thermal oxidation of copper powders under multiple heat treatment environments.

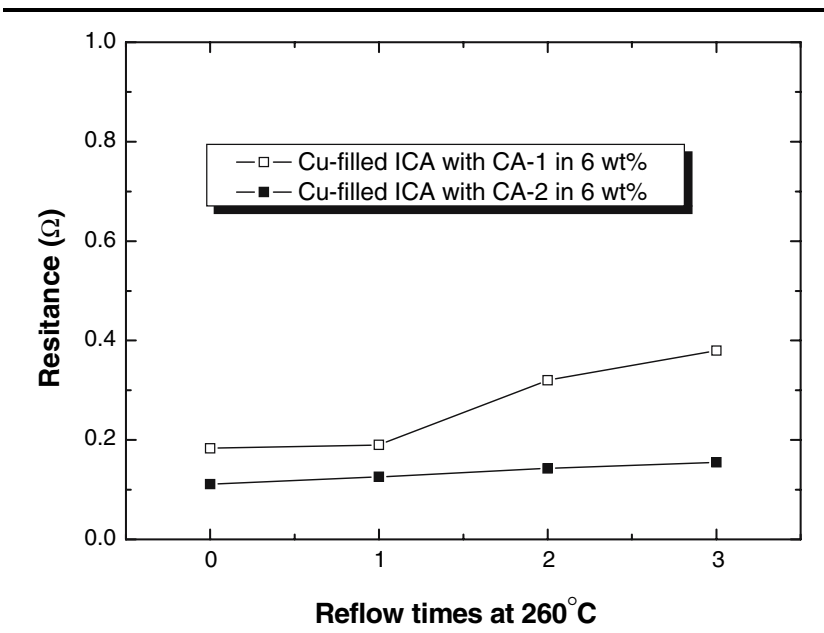

Fig. 7. Contact resistance behaviors of Cu-filled ICA joints with increasing number of reflow process.

\section{Bulk Resistivity of Cu-Filled ICA Under Harsh Environment}

Change in bulk resistivity for $\mathrm{Cu}$-filled ICAs with different CAs was monitored under $85^{\circ} \mathrm{C} / 85 \%$ relative humidity $(\mathrm{RH})$ and $85^{\circ} \mathrm{C} /$ dry aging for $24 \mathrm{~h}$, and the results were summarized in Table III.

The $\mathrm{Cu}$-filled ICA with CA 2 showed improved stability, even under the $85^{\circ} \mathrm{C} / 85 \% \mathrm{RH}$ aging test. This may have been due to the thermally stable CA layers and their anti-oxidant capability at elevated temperatures and humidities. Furthermore, the chemical bonding between the $\mathrm{CA}$ and the $\mathrm{Cu}$ particle surface reduced moisture absorption at the interface. The CA 2 may form a more hydrophobic surface on the $\mathrm{Cu}$ particles, and it promotes the reliable contact between $\mathrm{Cu}$ powders under conditions of high temperature and humidity.

In order to increase further the electrical conductivity of the $\mathrm{Cu}$-filled ICA, we incorporated bimodal sized $\mathrm{Cu}$ flakes. The use of different sized particles yields greater packing density, higher loading and tight contact between particles, providing improved electrical conduction paths in polymers. The bulk resistivity of Cu-filled ICAs with the mono- and bi-modal sized $\mathrm{Cu}$ flakes was measured with respect to the filler loadings, as shown in Table IV.

With the bimodal loading of $\mathrm{Cu}$ flakes and CA 2, a bulk resistivity of $\sim 10^{-4}(\Omega \mathrm{cm})$ was achieved. The enhancement of electrical conductivity by bimodal $\mathrm{Cu}$-filled ECAs is attributed to the decrease in interfacial contact resistance between $\mathrm{Cu}$ flakes.

\section{Interaction Between Coupling Agent and Copper Surfaces}

The effect of the duration of CA treatment on the contact angle was examined for different types and concentrations of the silane solution, as shown in Fig. 8.

The greater contact angle of the CA-coated surface than that of the neat $\mathrm{Cu}$ surface $\left(\sim 40^{\circ}\right)$ showed that the CA formed good monolayer coatings on the

Table III. Comparison of Bulk Resistivity and Reliability of Cu-Filled Isotropically Conductive Adhesives with Different Silane Coupling Agent

Sample

Cu-filled ICA with CA-1 as cured

$\mathrm{Cu}$-filled ICA with CA-2 as cured

$\mathrm{Cu}$-filled ICA with CA-1 after $85^{\circ} \mathrm{C} / 85 \% \mathrm{RH}$ for $24 \mathrm{~h}$

$\mathrm{Cu}$-filled ICA with CA-2 after $85^{\circ} \mathrm{C} / 85 \% \mathrm{RH}$ for $24 \mathrm{~h}$

$\mathrm{Cu}$-filled ICA with CA-1

after $85^{\circ} \mathrm{C} /$ dry for $24 \mathrm{~h}$

$\mathrm{Cu}$-filled ICA with CA-2

after $85^{\circ} \mathrm{C} /$ dry for $24 \mathrm{~h}$
Bulk Resistivity ( $\mathbf{2 c m})$

$1.70 \times 10^{-3}$ $1.28 \times 10^{-3}$

Very unstable

$$
\begin{aligned}
& 3.00 \times 10^{-3} \\
& 7.00 \times 10^{-3} \\
& 1.66 \times 10^{-3}
\end{aligned}
$$


Table IV. Comparison of Bulk Resistivity of CuFilled Isotropically Conductive Adhesives with Different Size Distribution of Filler

\section{Sample}

Cu-filled ICA with 1-5 $\mu \mathrm{m}$

$\mathrm{Cu}$ only, CA-2 as cured

Cu-filled ICA with bimodal

$\mathrm{Cu}$ loading, CA-2 as cured
Bulk Resistivity ( $\mathbf{c c m})$

$1.28 \times 10^{-3}$

$7.50 \times 10^{-4}$ metal surface, as shown in Fig. 9. The metallic $\mathrm{Cu}$ surface with basic hydroxyl group, M-OH, shows a low contact angle due to its hydrophilic property, as in Fig. 9a, and the organo-functional silane monolayer on the metallic $\mathrm{Cu}$ surface changes the surface chemistry, as in Fig. 9b. The silane monolayer eventually changes the surface energy and hydrophobicity, depending on the organic functional group. The organic functional group $(\mathrm{R})$ of $\mathrm{CA} 1$ is an aliphatic group, and the R of CA 2 is an aromatic
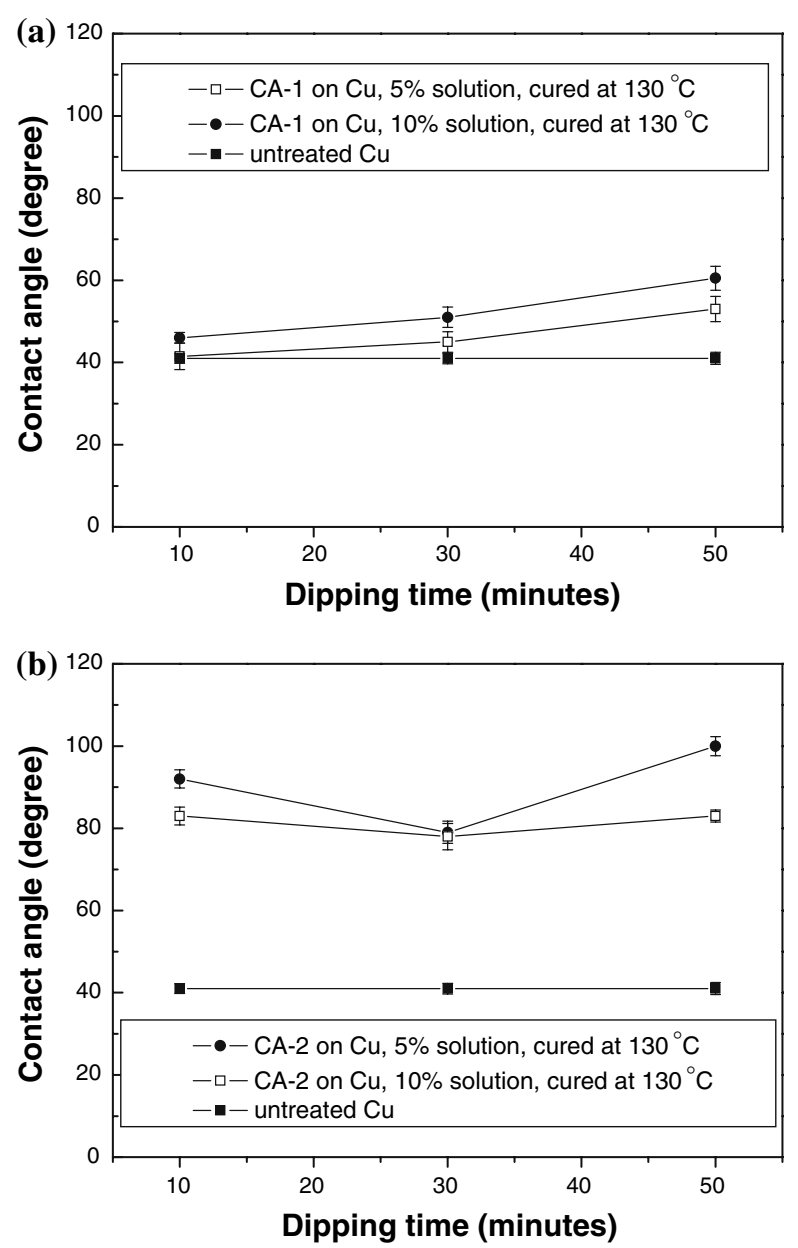

Fig. 8. Results on the contact angles of (a) CA 1-treated samples and (b) CA 2 treated samples and the average contact angle of the freshly cleaned untreated sample with variation in the dipping times.
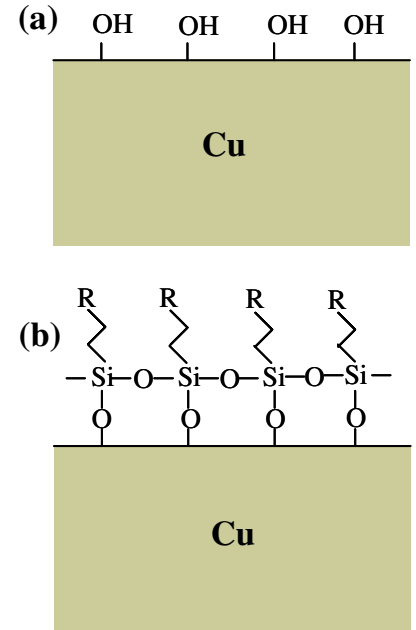

Fig. 9. Surface chemistry schematics of (a) neat Cu surface and (b) organo-functional silane-treated Cu surface.

group. Therefore, the results in Fig. 9 showed a clear difference in contact angles between CA 1 and CA 2 . The contact angles of the CA 2 layer $\left(80-100^{\circ}\right)$ were greater than those of the CA 1 layer $\left(40-60^{\circ}\right)$ on the $\mathrm{Cu}$ surfaces. This indicated that the CA 2-coated surface had more hydrophobicity than that of CA 1, due to the aromatic functional group, and this hydrophobic coating provided moisture-resistant coatings on a $\mathrm{Cu}$ surface. No clear relationships among the concentration of the silane solution, the dipping time and their contact angles were observed.

The effect of aging temperature on the contact angle of the silane coating layer was examined, as shown in Fig. 10. The contact angles of the CA 1-coated $\mathrm{Cu}$ surface slightly increased and remained almost constant at about $150-200^{\circ} \mathrm{C}$, while those of the CA 2-coated $\mathrm{Cu}$ surface decreased slightly but remained over $60^{\circ}$ at about $150-200^{\circ} \mathrm{C}$, without a rapid decrease. These results indicate that the silane coating layers on $\mathrm{Cu}$ are thermally stable up to $200^{\circ} \mathrm{C}$, without any degradation or desorption of the silane thin layer. This thermal stability may contribute to the stable contact resistances of the $\mathrm{Cu}$-filled ICA at high temperature ranges.

Overall, CA 2 produced a more hydrophobic surface, which is desirable for low moisture absorption. This finding supports the better performance of $\mathrm{Cu}$-filled ICA with CA 2 over that of CA 1 in the reliability test. This hydrophobic trend was most likely caused by the aromatic groups in CA 2 .

\section{CONCLUSION}

In order to achieve high performance $\mathrm{Cu}$-filled ICAs, the appropriate surface modification on the $\mathrm{Cu}$ flakes is very important if surface oxidation is to be avoided. We demonstrated high performance, low cost, $\mathrm{Cu}$-filled ICAs through the proper selection of the coupling agent and the in situ mixing with a matrix resin. 

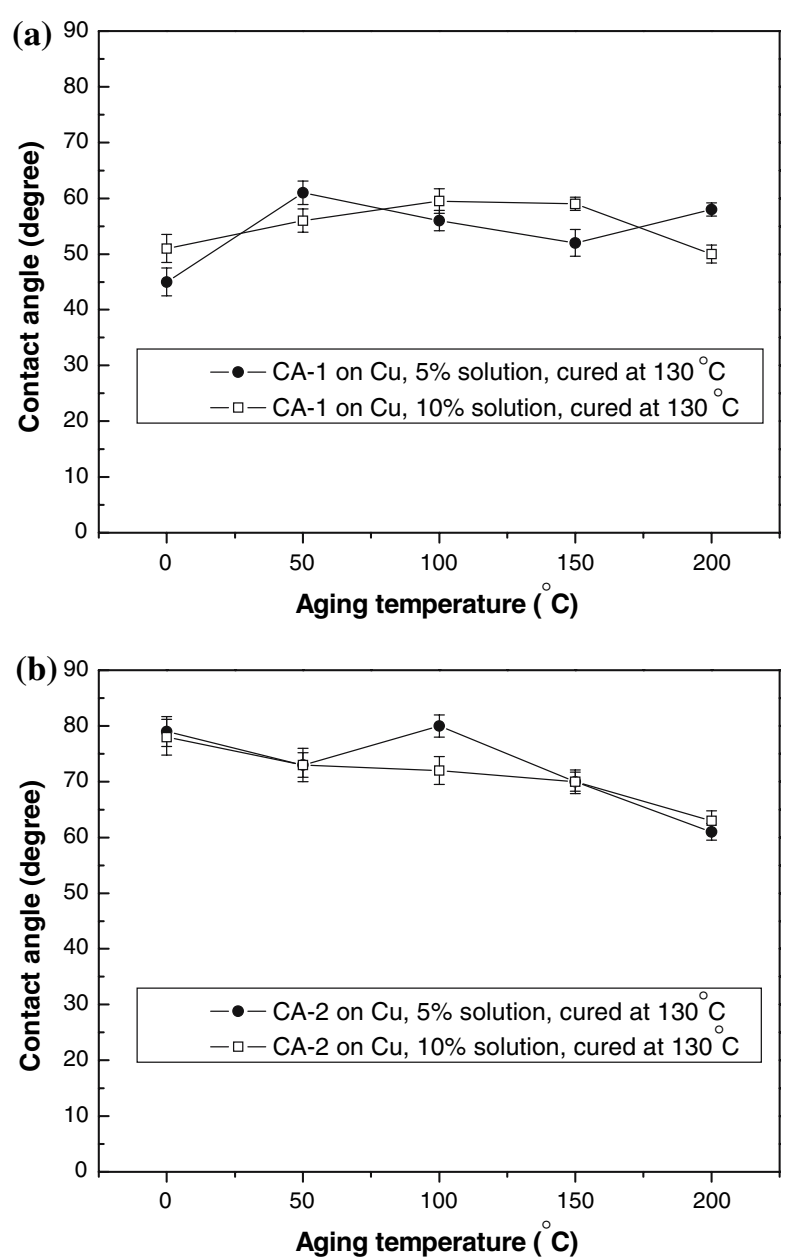

Fig. 10. The effect of aging temperature on contact angle for the samples of (a) CA 1 and (b) CA 2.

The effect of coupling agents on the prevention of oxidation of $\mathrm{Cu}$ metallic fillers for ICA materials, and the electrical and thermal performances and reliability of Cu-filled ICA joints, were investigated. It was found that the silane coupling agent was very effective in preventing the copper powder oxidation in ICA composite materials, and the improved thermal stability of $\mathrm{Cu}$-filled ICAs was achieved by optimized coupling agents. Bulk resistivity of a $\mathrm{Cu}-$ filled ICA with a silane coupling agent was achieved at $1.28 \times 10^{-3} \Omega \mathrm{cm}$.

Better reliability of the $\mathrm{Cu}$-filled ICA joint treated by a coupling agent with aromatic functionality was shown under $85^{\circ} \mathrm{C} / 85 \% \mathrm{RH}$ aging for $24 \mathrm{~h}$ than that of the $\mathrm{Cu}$-filled ICA joint treated by a coupling agent with aliphatic functionality. This was mainly due to more hydrophobicity and the high thermal stability of the monolayer of the coupling agent with the aromatic functional group on a copper surface from the contact angle behaviors at room temperature and elevated temperature. By the use of bimodal sized fillers and an optimized concentration of CA 2, low bulk resistivity, $7.5 \times 10^{-4} \Omega \mathrm{cm}$, was obtained.

\section{REFERENCES}

1. Y. Li, K. Moon, and C.P. Wong, Science 308, 1419 (2005).

2. Y. Li and C.P. Wong, Mater. Sci. Eng. $R$ 51, 1 (2006).

3. R.L. Dietz, et al., Solder. Surf. Mount Technol. 9, 55 (1997).

4. D. Cavasin, K. Brice-Heams, and A. Arab, Proceedings of the 53rd Electronic Components and Technology Conference (2003), p. 1404

5. R. Kisiel, J. Electron. Packaging 124, 367 (2002).

6. H. de Vries, J. van Delft, and K. Slob, IEEE Trans. Compon. Packaging Technol. 28, 499 (2005).

7. S.G. Hong and M.D. Ho, J. Environ. Sci. Health, Part A 34, 2043 (1999).

8. S.K. Kang, S. Buchwalter, and C. Tsang, J. Electron. Mater. 29, 1278 (2000).

9. Y.S. Tan, M.P. Srinivasan, and S.O. Pehkonen, J. Vac. Sci. Technol., A 22, 1917 (2004).

10. M.M. Sung, K. Sung, C.G. Kim, S.S. Lee, and Y. Kim, J. Phys. Chem. B 104, 2273 (2000).

11. T. Hatanaka and K. Nozaki, Japanese patent 62099483 (1987). 